\title{
5. Sınıf Fen Bilimleri Ders Kitabındaki Etkinliklerin Bilimsel Araştırma ve Mühendislik Tasarım Sürecine Göre İncelenmesi ${ }^{*}$
}

\section{The Investigation of 5th Grade Science Textbooks Activities in Terms of Scientific Inquiry and Engineering Design Process}

\section{Zeynep KOYUNLU ÜNLÜ ${ }^{* *}$}

Özgür ŞEN ${ }^{\star * *}$

\begin{abstract}
Öz. Ders kitapları öğrenme-öğretme sürecinde kullanılan temel gereçlerden biridir. Yenilenen öğretim programlarına göre hazırlanan ders kitaplarını incelemek, araştırmacılara, uygulayıcılara ve ders kitabı yazarlarına farklı bir bakış açısı kazandıracaktır. Bu araştırmanın amacı, 2017 Fen Bilimleri Dersi Öğretim Programına göre hazırlanan 5. sınıf ders kitabındaki etkinlikleri bilimsel araştırma ve mühendislik tasarım süreci basamaklarına göre analiz etmektir. Bu amaç doğrultusunda yöntem olarak doküman incelemesi kullanılmıştır. Ders kitabında yedi ünitede yer alan 51 etkinlik Bilimsel Araştırma Süreci ve Mühendislik Tasarım Süreci adımlarına göre analiz edilmiştir. Analiz sonucunda, ders kitabında bulunan etkinliklerde bilimsel araştırma sürecinden hipotez kurma, değişkenleri belirleme ve araştırma yapma basamaklarına diğer basamaklara oranla daha az yer verildiği; mühendislik tasarım süreci basamaklarına ise hiç yer verilmediği görülmüştür.
\end{abstract}

Anahtar Kelimeler: Fen eğitimi, ders kitapları, bilimsel araştırma süreci, mühendislik tasarım süreci

\begin{abstract}
Textbooks are one of the basic instruments used in the learning-teaching process. A close examination of textbooks prepared in accordance with the renewed curriculum give a different perspective to the researchers, practitioners and the authors. This study aims to analyze the activities included in the fifth-grade science textbook prepared on the basis of 2017 science curriculum in terms of Scientific Inquiry Process and Engineering Design Process. The method of document analysis was used for this purpose. Thus, 51 activities available in seven units of the textbook were analyzed according to scientific inquiry and engineering design process. Consequently, it was found that making hypotheses, determining the variables and doing research stages were emphasized less, also engineering design process stages have never been seen.
\end{abstract}

Keywords: Science education, textbooks, scientific inquiry process, engineering design process.

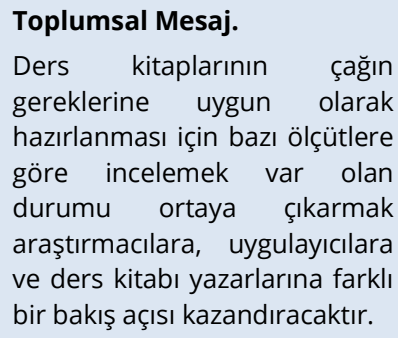
göre incelemek var olan durumu ortaya çıkarmak araştırmacılara, uygulayıcılara ve ders kitabı yazarlarına farklı bir bakış açısı kazandıracaktır.

Public Interest Statement. In order to prepare the textbooks according to the requirements of the age, examining them according to some criteria will give a different perspective to the researchers, practitioners and the authors of the textbooks.

\footnotetext{
* Bu araştırmanın özeti 25-26 Kasım 2017 tarihleri arasında düzenlenen Uluslararası Multidisipliner Çalışmaları Kongresi'nde sunulmuştur.

** Orcid ID: http://orcid.org/0000-0003-3627-1809, Yozgat Bozok Üniversitesi, Temel Eğitim Bölümü, Sınıf Eğitimi Anabilim Dalı, zeynepko.unlu@gmail.com

*** Orcid ID: http://orcid.org/0000-0002-8177-0984, Yozgat Bozok Üniversitesi, Matematik ve Fen Bilimleri Eğitimi Bölümü, Matematik Eğitimi Anabilim Dalı, senozgur@yahoo.com
} 


\section{GiRiş}

Fen Teknoloji Mühendislik ve Matematik (FeTeMM) ilk defa 1990 yılında Amerika Ulusal Bilim Vakfı (National Science Foundation [NSF]) tarafından kullanılan bir kısaltmadır (Bybee, 2013). Amerika Ulusal Bilim Vakfı, FeTeMM'i sadece matematik, doğal bilimler, mühendislik, bilgi ve iletişim teknolojileri değil sosyal/davranış bilimleri, psikoloji, ekonomi, sosyoloji ve politik bilimleri içeren geniş bir alan olarak tanımlamaktadır (Breiner, Harkness, Johnson ve Koehler, 2012). FeTeMM eğitimi farklı disiplinleri kullanarak günlük yaşamla ilgili problemlerin çözümüne yönelik bir ürün oluşturmaktır (Smith ve Karr-Kidwell, 2000). Bireylerin günümüz bilim ve teknoloji çağına ayak uydurabilmeleri için FeTeMM okuryazarı olarak yetişmeleri gerekmektedir. FeTeMM okuryazarlığı bir bireyin günlük yaşamla ilgili bir problemin çözümünde FeTeMM'le ilgili bilişsel ve duyuşsal özelliklerini kullanarak sonuca varması; araştırma-sorgulama ve tasarım biçimi olarak FeTeMM disiplinlerinin özelliklerini anlaması; FeTeMM disiplinlerinin kültürel çevremizi nasıl şekillendirdiğinin farkında olması; FeTeMM'le ilgili konularda ilgili ve istekli olmasıdır (Bybee, 2013).

Dejarnette (2012), FeTeMM alanlarında farkındalık ve ilgi için ilköğretim yıllarının en iyi zaman olduğunu belirtmiştir. Bu doğrultuda yurt dışında bazı ülkelerde FeTeMM eğitimlerinin verildiği okullar açılmış (Thomas ve Williams, 2009) öğrencilerin küçük yaşlardan itibaren bu alanlara yönelmeleri sağlanmıştır. Bu alanlardaki mesleklerden fen ile ilgili olanlar uzay bilimleri, yer bilimleri, yaşam bilimleri; teknoloji ile ilgili olanlar bilgisayar ve bilişim bilimleri; mühendislik ile ilgili olanlar mekanik, endüstri, elektrik, malzeme ve inşaat mühendislikleri; matematik ile ilgili olanlar cebir, geometri, istatistik ve oyun teorisidir.

Son yıllarda hazırlanan bir raporda ülkemizde 2023 yılında FeTeMM alanlarındaki istihdamının \%31'inin karşılanamayacağı belirtilmiştir. Ayrıca bu raporda FeTeMM alanlarının kritik rolüne değinilmiş, yenilikçiliğin temelini oluşturan FeTeMM becerilerinin ekonomik büyüme bakımından taşıdığı öneme dikkat çekilmiştir (Türkiye Sanayi ve İş Adamları Derneği [TüSiAD], 2017). Milli Eğitim Bakanlığı (MEB) tarafından hazırlanan raporda ise FeTeMM eğitiminin ne olduğu, nasıl ortaya çıktığı, çeşitli ülkelerde FeTeMM eğitimi ile ilgili yapılan çalışmalar, ülkemizdeki durum açıklanmış ve ülkemizde FeTeMM eğitimine geçiş için önerilerde bulunulmuş ayrıca bir eylem planı sunulmuştur (MEB, 2016).

FeTeMM eğitiminin uygulama yollarından biri Mühendislik Tasarım Sürecidir (MTS). Kelime olarak kökenine bakıldığında mühendis kelimesi tasarlamak anlamına gelen "ingenireya" ve akıllı buluş anlamına gelen "ingenium" kelimelerine dayanmaktadır. Bilim kelimesi de Latincedeki bilgi anlamına gelen "scientia" isminden türetilmiştir. Mühendislik insan yapımı bir dünyanın tasarlanması süreci iken bilim doğal dünyayı inceler. Bilim insanları sorular sorar, deneyler gerçekleştirir ve sorularının cevaplarına ulaşır, bilimsel araştırma sürecini kullanarak test edilebilir açıklamalarda bulunur. Mühendisler ise problemlerinin yanıtlarına ulaşmak için MTS kullanırlar. Bu aşamada mühendisler özel bir amaca hizmet ederler ve kendilerine "Kim neye neden ihtiyaç duyuyor?" sorusunu sorarlar. Farklı yollarla da olsa bilim insanları ve mühendisler bilimin gelişmesine katkıda bulunurlar. Bu iki alan birbirinin tamamlayıcısıdır. Bilim insanları dünya hakkında soru sorar. Mühendisler ise insanların istek ve ihtiyaçlarını karşılamak için dünyayı değiştirirler (Katehi, Pearson ve Feder, 2009; URL-1).

MTS problemin belirlenmesi, olası çözümlerin araştırılması, en uygun çözümün seçilmesi, prototipin yapılması ve prototipin test edilmesi aşamalarını içermektedir (Bozkurt, 2014). MTS karmaşık gibi görünmesine rağmen iletişim ve grup halinde çalışma becerisini desteklemektedir. Bu sürecin matematik ve fen derslerinde kullanımı ile günlük yaşamla ilişki kurulur. Ayrıca yaparakyaşayarak, eğlenceli bir öğrenme ortamı ile öğrenciler FeTeMM alanlarındaki mesleklere olumlu tutum geliştirebilirler (Moore, Stohlmann, Wang, Tank ve Roehrig, 2014). Yapılan araştırmalar MTS'nin derslerde kullanılmasının öğrencilerin bu alana yönelik başarılarını ve mühendislik mesleğine yönelik bilgi ve becerilerini geliştirdiğini göstermiştir (Çevik, 2017; Ercan ve Şahin, 2016; Yıldırım ve Altun, 2015). 
Ülkemizdeki fen bilimleri dersi öğretim programında araştırma-sorgulamaya dayalı öğrenme yaklaşımı benimsenmiştir (MEB-TTKB, 2006; MEB-TTKB, 2013; MEB-TTKB, 2017; MEB-TTKB, 2018). Araştırma-sorgulamaya dayalı öğrenme; öğrencilerin çevrelerindeki her şeyi keşfetme isteği duydukları, etraflarındaki doğal ve fiziksel dünyayı sağlam gerekçelerle açıklayıp bulunarak güçlü argümanlar kurdukları, fen bilimlerinden heyecan duyan ve değerini bilen bireyler olarak yetiştikleri, kısacası birer bilim insanı gibi yaparak-yaşayarak-düşünerek bilgiyi kendi zihninde oluşturduğu öğrenci merkezli bir öğrenme yaklaşımıdır (MEB, 2013, s. III). Araştırma-sorgulamaya dayalı öğrenme bilimsel araştırma sürecini (BAS) de içine alan bir yaklaşımdır. Tek bir BAS olmamakla beraber bu sürecin adımları genel hatları ile şu şekilde sıralanabilir: problemi belirler, araştırma yapar, hipotezini şekillendirir, değişkenleri belirler, deney tasarlar, yöntem belirler, deney yaparak hipotezini test eder, sonuçları değerlendirir ve yorumlar (MEB, 2017a).

Bilim ve mühendislikle ilgili olarak yapılacak etkinlikler öğrencilerin fen okur-yazarlığını geliştirir, bilişsel ve duyuşsal anlamda olumlu gelişmeler sağlar ve bu alanında kariyer bilinci geliştirmelerine de katkıda bulunur (Savran Gencer, 2015). Aşağıda yer alan Şekil 1'de BAS ve MTS döngüleri görülmektedir.

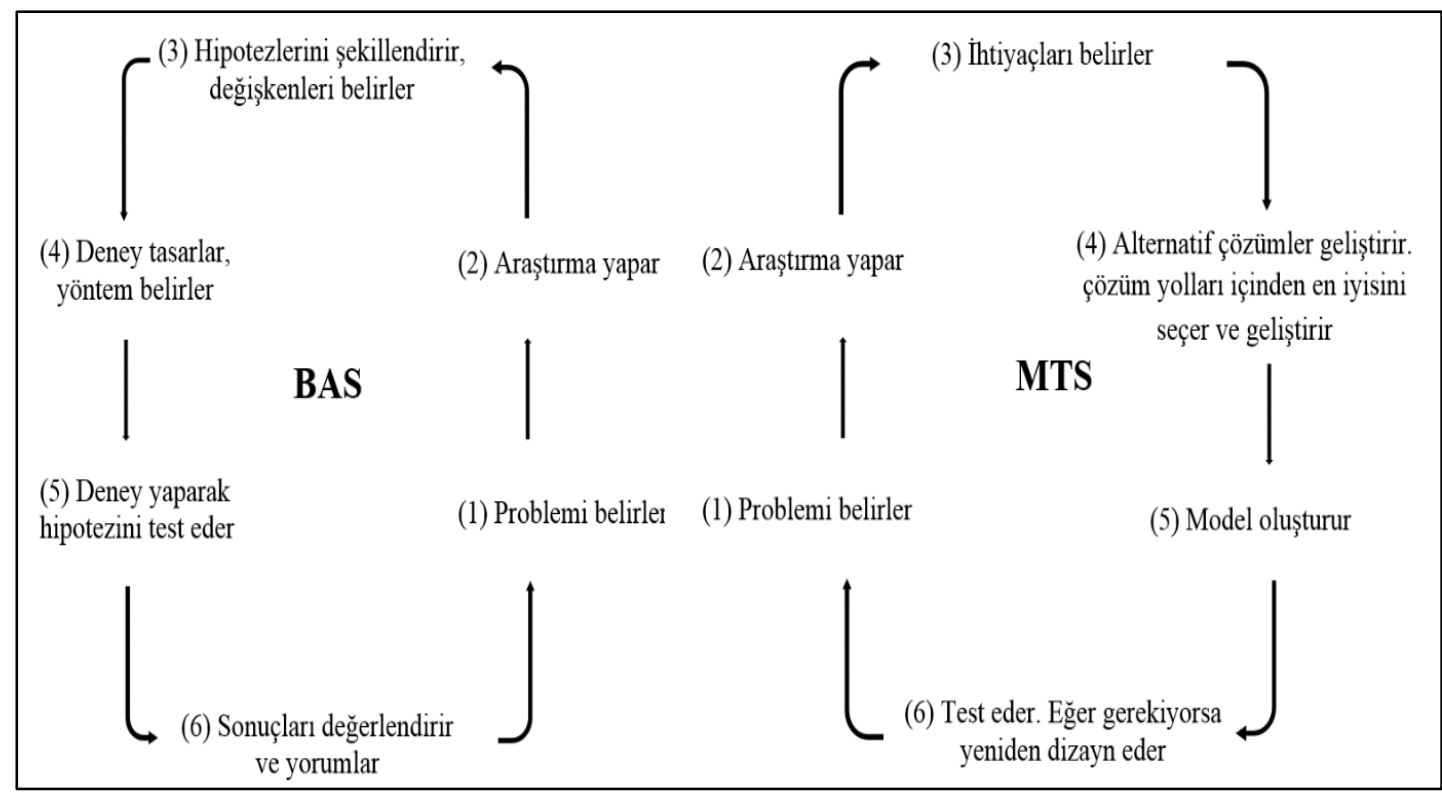

Şekil 1. BAS ve MTS basamakları

Şekil 1'den de görüldüğü gibi BAS ve MTS ortak basamaklara sahiptir. Bunlar problemin belirlenmesi ve araştırma yapılması basamaklarıdır. Bu basamaklar isim olarak aynı olsa da MTS'de bir ürün veya model oluşturmak, BAS'nde ise bilimsel bir sonuca varmaktır amaçlanır. MTS özünde üç temel unsuru içermektedir. Bunlar: (1) Problemin tanımlanması ve çözümü için ölçütlerin belirlenerek sınırlandırıması, (2) problemin çözümüne yönelik tasarımlar yapma ve (3) en iyi çözümü bulma (Next Generation Science Standarts [NGSS], 2013). Literatürde farkı adımlarından oluşan BAS ve MTS süreçlerine rastlamak mümkündür. Üzerinde durulması gereken önemli bir konu tek bir bilimsel araştırma ve mühendislik tasarım sürecinin olmadığıdır (Bozkurt Altan, 2017; NRC, 2012). BAS ile ilgili olarak bazı araştırmacılar bilimsel araştırmaların hepsinin bir soru ile başlayıp her zaman bir hipotez test etmediğine ve bilimsel araştırmalarda takip edilen tek bir bilimsel yöntem olmadığına dikkat çekmişlerdir (Lederman, Lederman, Bartos, Bartels, Meyer ve Schwartz, 2014). Genel hatları ile bu süreçlerin adımları aynıdır fakat bazı noktalarda farklıık görülebilmektedir. Bu süreçlerin adımlarında görülen farklılıklar araştırmanın amacı ve sınıf seviyesine uygunluktan kaynaklanabilmektedir (NGSS, 2013). 
Türkiye'de uygulanmış ve uygulanmakta olan Fen Öğretim programlarına bakıldığında BAS ve MTS'ye yer verildiği görülür. 2018'de Fen Bilimleri Dersi Öğretim Programı güncellenmiş ve “Fen, Mühendislik ve Girişimcilik Uygulamaları: Yıl Sonu Bilim Şenliği (Öğrencilerin yıl içerisinde ortaya çıkardıkları ürünü etkili bir şekilde sunmaları beklenir.)" ifadesine yer verilmiştir. Bu doğrultuda öğrencilerden yıl içinde işlenen konularla ilgili araç, nesne veya sistemleri geliştirmeleri beklenmiştir (MEB-TTKB, 2018). Güncellenen fen bilimleri dersi öğretim programı hakkında gerçekleştirilen çalışmalar, programda FeTeMM ile ilgili kazanımların mevcut olduğunu göstermiştir (Bahar, Yener, Yılmaz, Emen ve Gürer, 2018; Korkmaz, 2018).

Fen Bilimleri Öğretim programında yaşanan değişim ve gelişmelerle birlikte öğrenme-öğretme sürecinde kullanılan temel gereçlerden biri olan ders kitaplarında var olan durumu ortaya çıkarmak araştırmacılara, uygulayııılara ve ders kitabı yazarlarına farklı bir bakış açısı kazandıracaktır. Bu araştırmanın amacı, 2017-2018 eğitim-öğretim döneminde kullanılan 5. sınıf fen bilimleri ders kitabındaki etkinlikleri BAS ve MTS basamaklarına göre analiz etmektir.

\section{YÖNTEM}

Bu araştırmada 2017-2018 eğitim-öğretim döneminde uygulanmakta olan 5. sınıf fen bilimleri ders kitabındaki etkinlikler BAS ve MTS basamaklarına göre analiz edildiği için yöntem olarak nitel araştırma yaklaşımlarından doküman incelemesi kullanılmıştır. Doküman incelemesi veya analizi tek başına bir yöntem olabileceği gibi diğer nitel yöntemlerin kullanıldığı durumlara ek bilgi kaynağı da olabilir. Doküman incelemesi, araştırılması hedeflenen olgu veya olaylar hakkında bilgi içeren yazılı materyallerin analizini kapsamaktadır (Yıldırım ve Şimşek, 2006). Yazılı kaynaklar, kitaplar, dergiler, fermanlar, anılar, makaleler vb. olabilir (Sönmez \& Alacapınar, 2016). Bilgi kaynağı olarak doğrudan “5. Sınıf Fen Bilimleri Ders Kitabı (MEB, 2017a)" kullanıldı̆̆ı için bu araştırmanın yöntemi doküman incelemesidir.

Tepkiselliğin olmaması, etkinliklerin belirli bir çerçevede düzenlenmiş ve maliyetin düşük olması doküman incelemesinin bu araştırmadaki güçlü yönleridir. Sınırlı sözel olmayan davranış ve kodlama zorluğu ise doküman incelemesinin bu araştırmadaki zayıf yönleri olarak sıralanabilir (Yıldırım ve Şimşek, 2006).

\subsection{Veri Kaynağı ve Analizi}

Araştırmada incelenen doküman, veri kaynağı, 2017-2018 eğitim-öğretim döneminde uygulanmakta olan 5. sınıf fen bilimleri ders kitabındaki 51 etkinliktir (MEB, 2017a). Etkinliklerin çözümlenmesinde içerik ve betimsel analiz birlikte kullanılmıştır. İçerik analizinde temel amaç, verileri açıklayabilecek kavramlara ulaşmaktır. Betimsel analizdeki amaç ise elde edilen bulguları düzenlenmiş ve yorumlanmış bir biçimde okuyucuya sunmaktır (Yıldırım ve Şimşek, 2006).

5. Sınıf Fen Bilimleri Ders Kitabında "Güneş, Dünya ve Ay" adlı birinci ünitede 8, "Canlılar Dünyası" adlı ikinci ünitede 4, "Kuvvetin Ölçülmesi" adlı üçüncü ünitede 8, "Madde ve Değişim" adlı dördüncü ünitede 15, "Işı̆̆ın Yayılması" adlı beşinci ünitede 8, "Insan ve Çevre" adlı altıncı ünitede 5, "Elektrik Devre Elemanları adlı yedinci ünitede 3 olmak üzere toplam 51 etkinlik bulunmaktadır. Belirlenen etkinlikler yine aynı ders kitabında yer alan BAS ve MTS adımlarından yararlanılarak analiz edilmiştir. Tablo 1'de BAS ve MTS adımları (MEB, 2017a) ile bu adımların etkinliklerde ne derece temsil edildiğinin tespit edilmesi için araştırmacılar tarafından belirlenen ölçütler görülmektedir. 
Tablo 1. Bilimsel araştırma ve mühendislik tasarım süreci adımları (MEB, 2017a) ile araştırmacılar tarafından belirlenen ölçütler

\begin{tabular}{ll}
\hline Basamaklar & Ölçütler \\
\hline (1) Problemi belirler & $\begin{array}{l}\text { Bilimsel bilgiye ulaştırabilen problemlerin varlığı } \\
\text { incelenmiştir. }\end{array}$ \\
\hline (2) Araştırma yapma & $\begin{array}{l}\text { Problem veya araştırma konusu hakkında, etkinliğin } \\
\text { oğrenciyi araştırma yapmaya sevk etme durumu } \\
\text { incelenmiştir. }\end{array}$ \\
\hline $\begin{array}{l}\text { (3) Hipotez ve değişkenleri } \\
\text { belirler }\end{array}$ & $\begin{array}{l}\text { Etkinliklerde bağımlı ve bağımsı değişkenlerin varlığı } \\
\text { ve etkinliğin hipotez kurmaya uygunluğu incelenmiştir. }\end{array}$ \\
\hline $\begin{array}{l}\text { (4) Deneyin tasarlar ve yöntem } \\
\text { belirler }\end{array}$ & $\begin{array}{l}\text { Etkinliklerde bilimsel araştırmanın yapılabilmesi için } \\
\text { etkinlik adımların verilip verilmediği durumu } \\
\text { incelenmiştir. }\end{array}$ \\
\hline (5) Deneyin yapılması & $\begin{array}{l}\text { Etkinliğin öğrenciyi uygulama yapmaya sevk etme } \\
\text { durumu incelenmiştir. }\end{array}$ \\
\hline (6) Sonuçları değerlendirir ve & $\begin{array}{l}\text { Etkinliklerde sonuçlara ilişkin soruların veya etkinliğin } \\
\text { sonuçlarının yazılabileceği } \\
\text { incelenmiş̧tir. }\end{array}$ \\
yorumlar & $\begin{array}{l}\text { Tasarım problemlerinin varlığı incelenmiştir. } \\
\text { (1) Problemi belirler }\end{array}$ \\
\hline (2) Araştırma yapar & $\begin{array}{l}\text { Tasarım probleminin çözümü için etkinliğin öğrenciyi } \\
\text { araştırma yapmaya sevk etme durumu incelenmiştir. }\end{array}$ \\
\hline (3) ihtiyaçları belirler & $\begin{array}{l}\text { Etkinliğin gerçekleştirilmesi için bir amaç ya da } \\
\text { intiyacın belirtilme durumu incelenmiştir. }\end{array}$ \\
\hline (4)
\end{tabular}

MTS (4) Alternatif çözümler içerisinden en iyisini seçer

Etkinliğin farklı tasarımlar/fikirler arasından seçim yapmaya izin verme durumu incelenmiştir.

(5) Model oluşturur

Etkinliğin bir ürün, tasarım yapmaya izin verme durumu incelenmiştir.

(6) Test eder, eğer gerekliyse yeniden dizayn eder

Etkinliğin sonucunda geliştirilen ürünün denenmesi, varsa hataların belirlenmesi ve giderilmesi durumu incelenmiştir.

5. Sınıf Fen Bilimleri Ders Kitabındaki 51 etkinlik, Tablo 1'de yer alan BAS ve MTS basamaklarına göre analiz edilmiştir. Etkinliklerde bilimsel bilgiye ulaştırabilen problemlerin varlığı mevcut ise "(1) Problemi tanımlar" basamağına yer verildiği varsayılmıştır. Etkinliklerin tasarımı aşamalar halinde kitap tarafından öğrenciye sunulduğu için "(2) Araştırma yapar" ve "(3) Deney tasarlar, yöntem belirler" aşamalarına yer verildiği kabul edilmiştir. Eğer etkinlikte değişken varsa ve etkinlik hipotez kurmaya uygunsa "(5) Deney yaparak hipotezini test eder." aşamasına yer verildiği kabul edilmiştir. MTS için ise etkinlikte tasarım problemi var ise "(1) Problemi belirler", tasarım probleminin çözümü için etkinliğin öğrenciyi araştırma yapmaya sevk etme durumu var ise "(2) Araştırma yapar" basamaklarına yer verildiği varsayılmıştır. Etkinliğin gerçekleştirilmesi için bir amaç ya da ihtiyacın belirtilme durumu varsa "(3) İtiyaçları belirleme", farklı tasarımlar/fikirler arasından seçim yapmaya izin verme durumu varsa "(4) Alternatif çözümler geliştirir çözüm yolları içerisinden en iyisini seçer ve geliştirir", bir ürün, tasarım yapmaya izin verme durumu varsa "(5) Model oluşturur", sonucunda geliştirilen ürünün denenmesi, varsa hataların belirlenmesi ve giderilmesi durumu varsa "(6) Test eder. Eğer gerekliyse yeniden dizayn eder." basamağına yer verildiği kabul edilmiştir. Etkinliklerin analizini iki araştırmacı bireysel olarak gerçekleştirmişlerdir. Güvenirlik için, güvenirlik=(görüş birliği)/ (görüş birliği+görüş ayrılı̆̆ı) formülüne başvurulmuştur (Miles ve 
Huberman, 1994: 64). Araştırmacılar arasındaki uyum \%97 olarak hesaplanmıştır. Bulguların sunumu için ise araştırmacılar tartışarak fikir birliğine varmışlardır.

\section{BULGULAR}

2017-2018 eğitim-öğretim yılında okutulan 5. sınıf ders kitabındaki etkinliklerin ünitelere göre BAS ve MTS'ne göre analizi Tablo 2'de sunulmuştur.

Tablo 2. 5. Sınıf ders kitabındaki etkinliklerin BAS ve MTS basamaklara göre dağılımları

\begin{tabular}{|c|c|c|c|c|c|c|c|c|c|c|}
\hline \multicolumn{2}{|c|}{ BAS ve MTS Adımları } & \multicolumn{7}{|c|}{ Üniteler } & \multicolumn{2}{|c|}{ Toplam } \\
\hline & Basamaklar & 1 & 2 & 3 & 4 & 5 & 6 & 7 & $f$ & $\%$ \\
\hline \multirow{6}{*}{$\frac{n}{\infty}$} & (1) Problemin belirlenmesi & 2 & 1 & 1 & 7 & 2 & 2 & 2 & 17 & 33 \\
\hline & (2) Araştırma yapma & 0 & 0 & 0 & 0 & 0 & 0 & 0 & 0 & 0 \\
\hline & $\begin{array}{l}\text { (3) Hipotez ve değişkenlerin } \\
\text { belirlenmesi }\end{array}$ & 0 & 0 & 0 & 0 & 0 & 0 & 2 & 2 & 4 \\
\hline & $\begin{array}{l}\text { (4) Deneyin tasarlanması ve yöntemin } \\
\text { belirlenmesi }\end{array}$ & 8 & 4 & 7 & 15 & 8 & 5 & 3 & 50 & 98 \\
\hline & (5) Deneyin yapılması & 8 & 4 & 8 & 15 & 8 & 5 & 3 & 51 & 100 \\
\hline & $\begin{array}{l}\text { (6) Sonuçların değerlendirilip } \\
\text { yorumlanması }\end{array}$ & 8 & 4 & 7 & 15 & 8 & 5 & 3 & 50 & 98 \\
\hline \multirow{6}{*}{$\stackrel{n}{\Sigma}$} & (1) Problemin belirlenmesi & 0 & 0 & 0 & 0 & 0 & 0 & 0 & 0 & 0 \\
\hline & (2) Araştırma yapma & 0 & 0 & 0 & 0 & 0 & 0 & 0 & 0 & 0 \\
\hline & (3) İhtiyaçların belirlenmesi & 0 & 0 & 0 & 0 & 0 & 0 & 0 & 0 & 0 \\
\hline & $\begin{array}{l}\text { (4) Alternatif çözümlerin geliştirilmesi, } \\
\text { çözüm yolları içerisinden en iyisinin } \\
\text { seçilmesi }\end{array}$ & 0 & 0 & 0 & 0 & 0 & 0 & 0 & 0 & 0 \\
\hline & (5) Model oluşturma & 0 & 0 & 0 & 0 & 0 & 0 & 0 & 0 & 0 \\
\hline & $\begin{array}{l}\text { (6) Test etme, eğer gerekliyse yeniden } \\
\text { dizayn etme }\end{array}$ & 0 & 0 & 0 & 0 & 0 & 0 & 0 & 0 & 0 \\
\hline
\end{tabular}

Tablo 2'den de görüldüğü gibi 51 etkinliğin BAS ve MTS aşamalarından \%33 ( $f=17$ )'ünde problemi belirleme basamağına yer verilmiştir. Burada problemin belirlenmesi BAS basamakları ile ilgilidir. Çünkü öğrenciyi tasarım yapmaya iten bir problem durumunun varlığı etkinliklerde mevcut değildir. Bu nedenle etkinliklerde Tablo 1'de yer alan BAS basamlarından problemin belirlenmesi ölçütüne göre inceleme yapılmıştır (Bilimsel bilgiye ulaştırabilen problemlerin varlığı incelenmiştir.).

Etkinliklerde BAS'den hipotezini şekillendirir, değişkenleri belirler basamağına \%4 ( $f=2)$ oranında; deney tasarlar, yöntem belirler basamağına \% $98(f=50)$ oranında; deney/etkinlik yapar \%100 ( $f=51)$ oranında; sonuçları değerlendirir ve yorumlar basamağına \% $98(\mathrm{f}=50)$ oranında yer verildiği; araştırma yapar basamağına ise hiç yer verilmediği görülmektedir. İncelenen ders kitabındaki bazı etkinliklerde bağımlı ve bağımsız değişkenler yer aldığı için bu etkinlikler hipotez kurmaya uygundur (3. Ünite: Lastikteki Değişimi Gözlemleyelim, Dinamometreyle Kuvvet Ölçelim, Sürtünme Tüm Yüzeylerde Aynı Mıdır?, İç içe Geçen Sayfalar, Hava Ortamında Sürtünme Kuvveti, Su Direncini Hissedelim; 4. Ünite: Erime Noktası ve Donma Noktasını Keşfedelim, Erime Noktası ve Erime Süresi, Hangisi Daha Çabuk Erir, Paraya Ne Oldu?, Balona Ne Oldu?; 5. Ünite: Dalgalanan Görüntüler, Çiçeği Gördük Mü?, Gölge Boyunu Gözlemleyelim; 6. Ünite: Doğayı Keşfedelim, Hava Nasıl Oralarda?, Dünyanın İklimi Değişiyor Mu? Nasıl?). Fakat hipotez kurmaya sadece 7. ünitede bulunan etkinliklerde (Basit Bir Elektrik Devresi Kuralım, Bir Elektrik Devresindeki Ampul Parlaklığını Nasıl Değiştirebiliriz?, Pil Sayısı Ampul Parlaklı̆ıını Nasıl Etkiler?) değinilmiştir. 
Diğer yandan MTS'den hiçbir basamağa yer verilmemiştir. Aşağıda yer alan Şekil 2'deki etkinlikte BAS basamaklarının temsil edilme durumu görülmektedir.

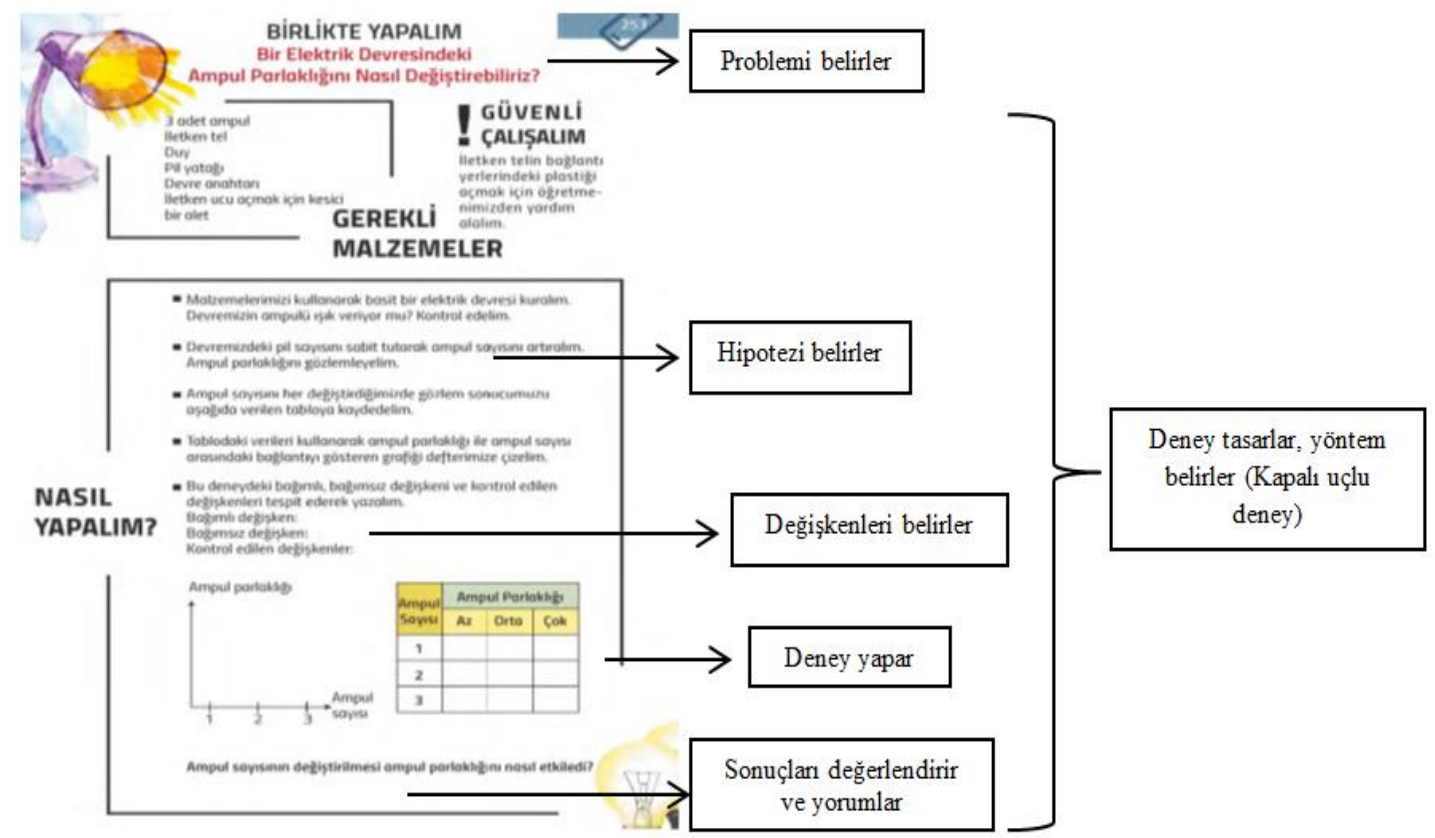

Şekil 2. 5. Sınıf Fen Bilimleri Ders Kitabındaki bir etkinliğe ait örnek analiz (MEB, 2017a: 253)

Şekil 2'de BAS basamakların en fazla yer aldığı bir etkinlik görülmektedir. "Bir Elektrik Devresindeki Ampul Parlaklığını Nasıl Değiştirebiliriz?" adlı bu etkinlikte ampulün parlaklığını değiştiren etmenlerin incelenmesi bir problem durumu oluşturmuştur. Dolayısı ile bu etkinlikte BAS'nden "Problemi belirler" basamağına yer verilmiştir. Bu etkinlik öğrenciyi ampulün parlaklığını değiştiren etmenleri incelenme eylemine sevk ettiği için bir hipotez deneyidir. Etkinlikte öğrencilerin hipotez kurmasını sağlayan bir bölüm yoktur. Fakat etkinliğin "Nasıl yapalım?" bölümünde "Devremizdeki pil sayısını sabit tutarak ampul sayısını artıralım. Ampulün parlaklığını gözlemleyelim." ifadesinin yer alması bağımsız değişkenin, bağımlı değişken üzerindeki etkisini incelemeye izin verdiği için hipotezdir. Etkinlikte bağımlı, bağımsız ve kontrol edilen değişkeni belirleme kısmı öğrenciye bırakılmıştır. Değişkenleri belirler aşamasına yer verilmiştir. Öğrencinin etkinliği yaparak elde ettiği sonuçlarla tablo ve grafiği doldurması beklenmiştir. Burada öğrencinin deney yapması gerekmektedir. Etkinliğin son kısmında "Ampul sayısının değiştirilmesi ampul parlaklığını nasıl etkiledi?" sorusunun yer alması öğrenciyi sonuçları değerlendirme ve yorumlama fırsatı sunmuştur. Etkinliğin tüm adımları kitap tarafından sunulduğu için kapalı uçludur.

Aşağıda yer alan Şekil 3'te kitapta yer alan başka bir etkinlikte BAS basamaklarının temsil edilme durumu görülmektedir. 


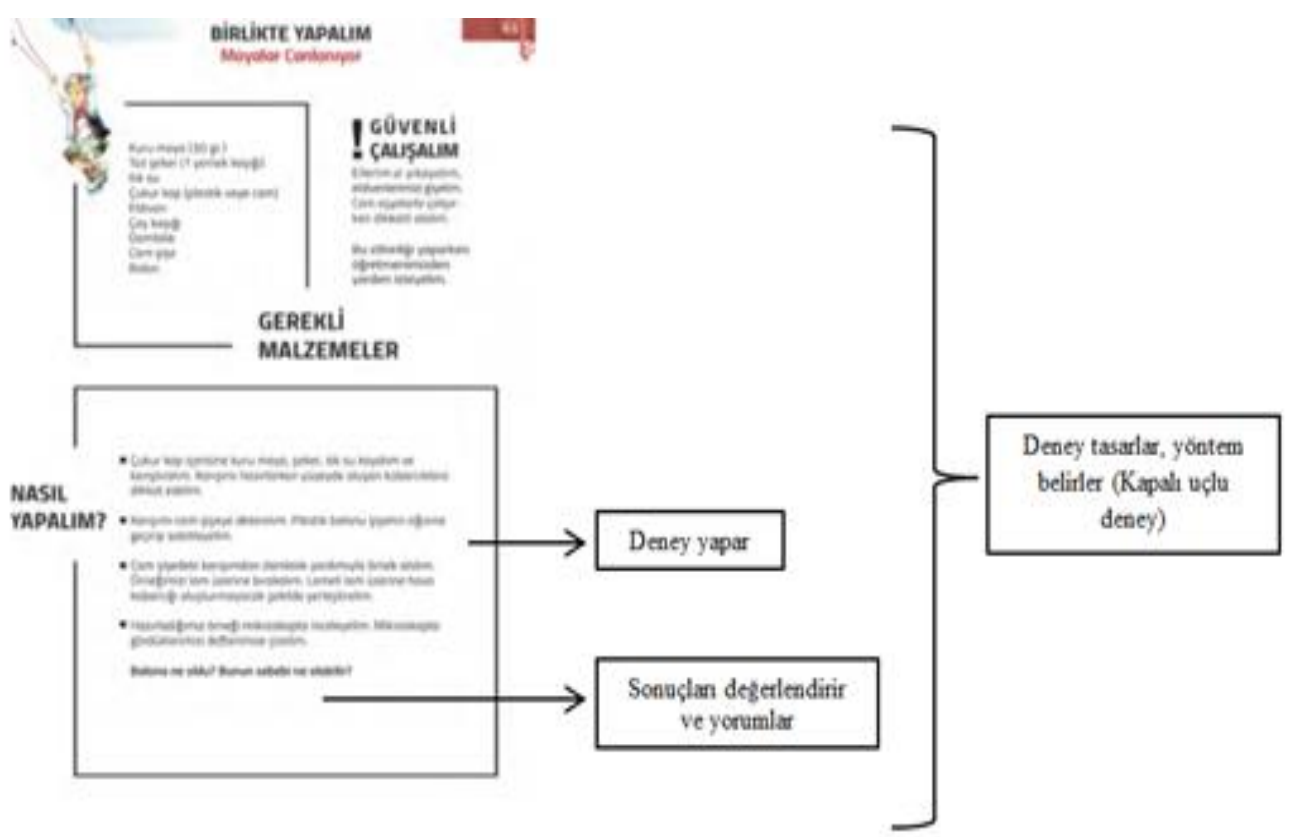

Şekil 3. 5. Sınıf Fen Bilimleri Ders Kitabındaki bir etkinliğe ait örnek analizler (MEB, 2017a, s.63)

Şekil 3'te yer alan "Mayalar Canlanıyor" adlı etkinlik mikroskobik canlıların oksijensiz solunum sonucunda karbondioksit gazı ürettiklerini öğretmeyi amaçlamaktadır. Araştırmanın konusu yani bellidir fakat etkinlikte bir problem cümlesi olmadığı için "Problemi Belirler" aşamasına yer verilmemiştir. Etkinlikte hangi malzemelerin kullanılacağı, amaca ulaşmak için hangi basamakların izleneceği yer aldığından bu etkinlik kapalı uçludur. Etkinliğin son kısmında "Balona ne oldu? Bunun sebebi nedir?" sorusunun yer alması öğrenciyi sonuçları değerlendirme ve yorumlama fırsatı sunmuştur. Bu doğrultuda Şekil 3'te yer alan etkinlikte deney tasarlama, yöntem belirleme ile sonuçları değerlendirir ve yorumlar basamaklarına yer verilmiştir.

\section{SONUÇ VE ÖNERILER}

2017-2018 eğitim-öğretim yılında MEB okullarında okutulmakta olan 5. sınıf fen bilimleri ders kitabındaki etkinlikleri BAS ve MTS basamaklarına göre analiz etmeyi amaçlayan bu araştırmada ders kitabındaki yedi ünitede bulunan 51 etkinlik incelenmiştir. Sonuç olarak etkinliklerde bilimsel araştırma sürecinden hipotez kurma, değişkenleri belirleme basamaklarına diğer basamaklara oranla daha az yer verildiği; mühendislik tasarım süreci basamaklarına ise yer verilmediği görülmüştür.

Etkinliklerde, uygulamaya başlamadan önce genel olarak öğrencilerden tahminde bulunmaları istenmiştir. Bu bakımdan etkinlikler öğrencilerin tahmin ve hipotezin farkını anlamalarını sağlayacak şekilde düzenlenmemiştir. Tahmin var olan bilgilerin kullanılarak gelecekteki olaylar ya da olması muhtemel yeni durumlar hakkında fikir belirtmek iken hipotez bağımlı ve bağımsız değişken arasındaki ilişki hakkındaki geçici tahminlerdir. Hipotez kurmak için bağımlı ve bağımsız değişkenlerin belirlenmesi gereklidir (Karslı, 2017). Incelenen ders kitabındaki bazı etkinliklerde bağımlı ve bağımsız değişkenler yer aldığı için bu etkinlikler hipotez kurmaya uygundur. Fakat hipotez kurmaya sınırlı sayıdaki etkinlikte yer verilmiştir. 5. Sınıf Bursluluk Sınavlarında öğrencilere değişkenler ve hipotez kurmayla ilgili soruların yöneltildiği (MEB, 2017b) göz önünde bulundurulduğunda kitabın bu becerilere göre düzenlenmemesi bir eksikliktir denilebilir. Son yıllarda gerçekleştirilen bir araştırmada 2015-2016 öğretim yılında ortaokullarda okutulması zorunlu olan beşinci sınıf fen bilimleri ders kitabı incelenmiş̧ir. Araştırma sonucunda ders kitabının 
verilerin toplanması, temsili ve verilerden yola çıkarak tahminde bulunma konularında öğrencilere yeterli fırsat tanımadığı ortaya çıkmıştır (Özdemir ve Yanık, 2017).

Kitap etkinlikleri tasarlanmış bir biçimde kapalı uçlu olarak, vermiştir. Öğrenciye etkinliği tasarlama fırsatı verilmemiş̧ir. Bu şekilde gerçekleştirilen kapalı uçlu deneyler vakit kaybını önlemekle birlikte öğrencilerin yaratıcı düşünmelerini kısıtlamaktadır (Martin-Hansen, 2002). Son olarak 2018'de güncellenen fen bilimleri dersi öğretim programında FeTeMM ile ilgili kazanımlar mevcuttur (Bahar, Yener, Yılmaz, Emen ve Gürer, 2018; Korkmaz, 2018). Fakat incelenen ders kitabındaki etkinliklerde MTS basamaklarına hiç yer verilmemesi ders kitabının sınırlılıklarındandır denilebilir. Diğer yandan 2018'de güncellenen Fen Bilimleri Öğretim Programında “Fen, Mühendislik ve Girişimcilik Uygulamaları" öğrenme alanı tüm yıla yayılmış olması ile 2018-2019 eğitim-öğretim yılından sonra okutulacak olan ders kitaplarındaki etkinliklerde MTS ile ilgili etkinliklere yer verileceği düşünülmektedir.

MTS etkinliklerini uygulama sürecinde öğretmen rolünün etkisi büyüktür. Bu noktada öğrencilerin STEM alanlarına ilgilerinin çekilebilmesi için programın uygulayıııları olan öğretmenlerin yeterli uzmanlığa sahip olmaları gerekmektedir. Mühendislik genellikle öğretmenler tarafından ayrı bir alan olarak görülür. Tek ve net bir cevabı olmayan problemlerin çözümlerinde oluşabilecek açık uçlu durumlardan dolayı öğretmenler MTS'yi uygulamak istemeyebilirler. Mühendislik kavramlarına ve mesleğine aşina olmadıkları için MTS'ni uygulama konusunda kaygı ve korku taşırlar (Katehi, Pearson ve Feder, 2009). Araştırmalar öğretmen ve öğretmen adaylarının MTS ve BAS uygulamaları konularında pedagojik alan bilgilerinin eksik olduğunu göstermiştir (Dejarnette, 2012). Fakat alınan eğitimler, yapılan uygulamalar öğretmenlerin mühendislik tasarım temelli etkinlikleri uygulama konusuna olumlu bakmalarını ve bu konuda istekli davranmalarını sağlayabilir (Hacıoğlu, Yamak ve Kavak, 2016).

Ders kitaplarının çağın gereklerine uygun olarak hazırlanması için bazı ölçütlere göre incelenmesi var olan durumun ortaya çıkarılması araştırmacılara, uygulayıcılara ve ders kitabı yazarlarına fikir sağlayacaktır. Diğer yandan tek bir kitabın araştırmacılar tarafından belirlenen ölçütlere göre incelenmesi bu araştırmanın sınırlııklarıdır.

\section{5. ÖNERILER}

Araştırma sonuçlarından yola çıkarak aşağıdaki önerilerde bulunulmuştur:

- Ortaokul fen bilimleri ders kitaplarında hipotez kurma ve değişkenleri belirlemeye uygun olan etkinliklerin bu bağlamda öğretilmesi öğrencilerin bilimsel araştırma becerilerini, bilimsel süreç becerilerini geliştirebilir aynı zamanda sınavlara hazırlanmalarını sağlabilir.

- Ders kitabındaki etkinlikler öğrencilerin BAS ve MTS basamaklarını anlayabileceği biçimde düzenlenebilir.

- BAS ve MTS basamaklarına uygun etkinlikler yapılırken tek bir BAS ve MTS döngüsünün olmadığı öğrencilere hissettirilmelidir.

- Kitabın uygulayıcıları olan öğretmenler, 5. Sınıf Fen Bilimleri Ders Kitabı'nda yer alan etkinlikleri bilimsel araştırmanın doğasını anlamaya yönelik uygulayabilirler.

Fen bilimleri ders kitaplarındaki etkinlikler farklı ölçütlere göre incelenebilir.

\section{Kaynakça}

Bahar, M., Yener, D., Yılmaz M. ve Emen, H., Gürer, F. (2018). 2018 Fen bilimleri öğretim programı kazanımlarındaki değişimler ve fen teknoloji matematik mühendislik (STEM) entegrasyonu. Abant Izzet Baysal Üniversitesi Eğitim Fakültesi Dergisi, 18(2), 702-735. 
Bezir Akçay, B. (2016). Bilimde paradigmalar ve bilimin doğası. Fen Bilimleri Öğretimi (Ed. Anagün, Ş. S., Duban, N., s. 37-54), Anı yayıncilık, Ankara.

Bozkurt Altan, E. (2017). Disipliner yapıdaki derslerde STEM eğitimi: tasarım temelliöğrenme ve probleme dayalı STEM uygulamaları. Fen, teknoloji, mühendislik ve matematik (FeTeMM-STEM) eğitimi (Ed. Salih Çepni), Ankara: Pegem Akademi Yayınları.

Bozkurt, E. (2014). Mühendislik tasarım temelli fen eğitiminin fen bilgisi öğretmen adaylarının karar verme becerisi, bilimsel süreç becerileri ve sürece yönelik algılarına etkisi. Doktora Tezi. Gazi Üniversitesi, Ankara.

Bybee, R. W. (2013). The case for STEM education: challenges and opportunities. National Science Teachers Association, NSTA Press, Arlington, Virginia.

Breiner, J. M., Harkness, S. S., Johnson, C. C. ve Koehler, C. M. (2012). What is STEM? A discussion about conceptions of STEM in education and partnerships. School Science and Mathematics, 112 (1), 3-11.

Bybee, R. W. (2013). The case for STEM education challenges and opportunities. National Science Teacher Association Press, Virginia.

Çevik, M. (2017). Impacts of the Project Based (PjB) Science, Technology, Engineering and Mathematics (STEM) Education on Academic Achievement and Carrier Interests of Vocational High School Students. Pegem Eğitim ve Öğretim Dergisi, $O(x x x)$. Retrieved from http://www.pegegog.net/index.php/pegegog/article/view/343

Dejarnette, N. K. (2012). America's children: providing early exposure to STEM (Science, Technology, Engineering and Math) initiatives. Education, 133(1), 77-84.

Ercan, S. ve Şahin, F. (2016). Fen eğitiminde mühendislik uygulamalarının kullanımı: tasarım temelli fen eğitiminin öğrencilerin akademik başarıları üzerine etkisi. Necatibey Eğitim Fakültesi Elektronik Fen ve Matematik Eğitimi Dergisi, 9(1), 128-164.

Hacıoğlu, Y., Yamak, H. ve Kavak, N. (2016). Mühendislik tasarım temelli fen eğitimi ile ilgili öğretmen görüşleri. Bartın Üniversitesi Eğitim Fakültesi Dergisi, 5(3), 807.

Karışan, D., Bilican, K. ve Şenler, B. (2017). Bilimsel sorgulama hakkında görüş anketi: Türkçeye uyarlama, geçerlik ve güvenirlik çalışması. Inönü Üniversitesi Eğitim Fakültesi Dergisi, 18(1), 326343.

Karslı, F. (2017). Fen eğitiminde bilimsel süreç becerileri. Fen Bilimleri Öğretimi (Ed. Demirci, Güler, M., s. 29-44), Pegem Akademi, Ankara.

Katehi, L., Pearson, G. ve Feder, M. (Eds.). (2009). Engineering in K-12 education: Understanding the status and improving the prospects (Committee on K-12 Engineering Education, National Academy of Engineering and National Research Council). Washington, DC: National Academies Press.

Korkmaz, F. (2018). STEM Education and its reflection on the secondary school science lesson draft curriculum. Pegem Eğitim ve Öğretim Dergisi, 8(3), 439-468.

Lederman, J. S., Lederman, N. G., Bartos, S. A., Bartels, S. L., Meyer, A. A. ve Schwartz, R. S. (2014). Meaningful assessment of learners' understandings about scientific inquiry-the views about scientific inquiry (VASI) questionnaire. Journal of Research in Science Teaching, 51(1), 65-83.

Martin-Hansen, L. (2002). Defining inquiry. The Science Teacher, 69(2), 34-37.

MEB. Yenilik ve Eğitim Teknolojileri Genel Müdürlüğü (YEĞiTEK). (2016). STEM Eğitimi Raporu. Ankara.

MEB-TTKB. (2006). ilköğretim fen ve teknoloji dersi (3, 4, 5, 6, 7 ve 8. sınıflar) öğretim programı. Ankara.

MEB-TTKB. (2013). ilköğretim kurumları (ilkokullar ve ortaokullar) fen bilimleri dersi (6, 7 ve 8 . sınıflar) öğretim programı. Ankara. 
MEB-TTKB. (2017). Ilköğretim kurumları (ilkokullar ve ortaokullar) fen bilimleri dersi (3, 4, 5, 6, 7 ve 8. sınıflar) öğretim programı. Ankara.

MEB-TTKB. (2018). ilköğretim kurumları (ilkokullar ve ortaokullar) fen bilimleri dersi (3, 4, 5, 6, 7 ve 8. sınıflar) öğretim programı. Ankara.

MEB. (2017a). Ortaokul fen bilimleri ders kitabı 5. Ankara.

MEB. (2017b). ilköğretim ve ortaöğretim kurumları bursluluk soruları. http://odsgm.meb.gov.tr/meb_iys_dosyalar/2017_06/12165251_5_SINIF_A.pdf

Miles, M.B. ve Huberman, A.M. (1994). Qualitative data analysis. Thousand Oaks, CA: Sage.

Moore, T. J., Stohlmann, M. S., Wang, H.-H., Tank, K. M., Glancy, A. W. ve Roehrig, G.H. (2014). Implementation and integration of engineering in K-12 STEM education. In $\quad$ S. Purzer, J. Strobel \& M. Cardella (Eds.), Engineering in precollege settings: Research into practice (pp. 35-60). West Lafayette, IN: Purdue University Press

Next Generation Science Standarts. (2013). Understanding the scientific enterprise: the nature of science in the next generation science standards. Washington, DC: The National Academies.

National Research Council [NRC]. (2012). A framework for k-12 science education: practices, crosscutting concepts, and core ideas. Washington DC: The National Academic Press.

Özdemir, G. ve Yanık, H. B. (2017). Beşinci sınıf fen bilimleri ders kitabında yer alan etkinliklerin veriler açısından incelenmesi. Ahi Evran Üniversitesi Kırşehir Eğitim Fakültesi Dergisi (KEFAD), 18, 203-221.

Ramaley, J. A. (2009). The national perspective: fostering the enhancement of STEM undergraduate education. New Directions for Teaching and Learning, 117, 69-81.

Savran Gencer, A. (2015). Fen eğitiminde bilim ve mühendislik uygulaması: fırıldak etkinliği. Araştırma Temelli Etkinlik Dergisi (ATED), 5(1), 1-19.

Smith, J. ve Karr-Kidwell, P. (2000). The interdisciplinary curriculum: a literary review and a manual for administrators and teachers. https://eric.ed.gov/?id=ED443172

Sönmez, V. ve Alacapınar, F. G. (2016). Bilimsel araştırma yöntemleri. Ankara: Anı Yayıncılık.

Thomas, J., ve Williams, C. (2009). The history of specialized STEM schools and the formation and role of the NCSSSMST. Roeper Review, 32(1), 17-24.

TÜSIAD ve PwC. (2017). 2023'e Doğru Türkiye'de STEM Gereksinimi. Ankara.

Yıldırım, A. ve Şimşek, H. (2006). Sosyal bilimlerde nitel araştırma yöntemleri. Ankara: Seçkin.

Yıldırım, B., ve Altun, Y. (2015). STEM eğitim ve mühendislik uygulamalarının fen bilgisi laboratuvar dersindeki etkilerinin incelenmesi. El-Cezeri Journal of Science and Engineering, 2(2).

URL-1.http://ssds-science.weebly.com/science-inquiry-and-engineering-designprocesses.html 


\section{Extended Summary}

The abbreviation STEM (Science, Technology, Engineering, and Mathematics) was first used in 1990 by National Science Foundation (NSF) (Bybee, 2013). One of the ways in which STEM is implemented is Engineering Design Process (EDP). The steps to be taken in this process involve determining the problem, investigating the potential solutions, selecting the most suitable solution, creating the prototype and testing the prototype (Bozkurt, 2014). Associations are set up with daily life with the use of the process in classes. Besides, students can also develop positive attitudes towards careers in the field of STEM with entertaining learning environments where they can learn by doing and experiencing (Moore, Stohlmann, Wang, Tank \& Roehrig, 2013). On the other hand, Scientific Inquiry Process (SIP) is also important. The eight components of scientific inquiry that should be understood by teachers, prospective teachers and students are listed as in the following (Lederman et al., 2014): (1) scientific inquiry begins with a question and it is not always tested by one hypothesis, (2) there is no one single scientific inquiry employed in all scientific inquiry, (3) the question asked guides the inquiry process, (4) scientists applying the same procedures may not obtain the same results, (5) inquiry process influences the results, (6) research results have to be consistent with the data collected, (7) scientific data and scientific evidence are not the same thing, (8) inferences are made on the basis of collected data and on the basis of what is known beforehand.

While EDP aims to create more than one outcome, the process of SIP aims to reach a conclusion. What is common to both processes is that they both determine the problem and that they both do research. Shaping the hypothesis, determining the variables, designing experiments, determining a method, testing the hypothesis by doing experiments, evaluating and interpreting the results are the stages of scientific inquiry process. Determining the needs, developing alternative solutions, selecting the best of the solutions and developing it, creating models, testing them and re-designing them when necessary are the stages of engineering design process.

Science and Engineering Applications learning domain was included physical sciences curriculum updated in 2017 in addition to the learning domains of the World and Universe, Living Organisms and Life, Physical Events, and Substance and Its Nature. Thus, STEM approach was included in 2017 physical sciences curriculum. It will gain a different point of view for researchers, practitioners and textbook authors to reveal the existing situation in textbooks, which is one of the basic tools used in the learningteaching process as well as changes and developments in science curriculum. Analyzing course books prepared in accordance with the renewed curriculum will raise the quality of course books and thus of the teaching process. This study aims to analyze the activities included in the course books prepared on the basis of the curriculum implemented for the first time with 5th graders according to SIP and EDP.

This study employs document analysis-one of qualitative research approaches. The document analyzed is "5th grade physical sciences course book" (Ministry of National Education, 2017) prepared according to 2017 curriculum for physical sciences course. All the activities in 5th grade physical sciences course book were determined for data analysis on the basis of units. The activities determined were analyzed according to the stages of scientific inquiry process (determining the problem, doing research, shaping the hypothesis, determining the variables, designing experiments, determining a method, testing the hypothesis by doing experiments, evaluating and interpreting the results) and of engineering design process (describing the problem, doing research, determining the needs, developing alternative solutions, selecting the best of the solutions and developing it, creating models, testing them and redesigning them when necessary) included in the course book. The stages (1) determining the problem, and (2) doing research- which were the stages of both scientific inquiry process and engineering design process- were considered to be included.

Content analysis was used for data analysis. The two researchers formed the categories individually. The formula reliability=agreement/agreement + disagreement was used for reliability analysis (Miles and Huberman, 1994, p. 64). Agreement between the researchers was calculated as $97 \%$. For the presentation of findings, the researchers reached agreement by discussing.

51 activities in the textbook were analyzed according to scientific inquiry and engineering design process. Stages of determining the problem $33 \%(f=17)$ in the activities. Of the stages of scientific inquiry, shaping the hypothesis was included in the activities, determining the variables was included in the 
activities at the rate of $4 \%(f=2)$, designing experiments at the rate of $98 \%(f=50)$, doing experiments at the rate of $100 \%(f=51)$ and evaluating and interpreting the results at the rate of $98 \%(50)$. On the other hand, doing research the stages of engineering design process stages weren't included in the activities.

In conclusion, it was found that making hypotheses, determining the variables and doing research stages were emphasized less, also engineering design process stages have never been seen.

At the beginning of the activities, students were generally asked to make predictions. The activities were not organised in a manner to enable students to see the difference between predictions and hypotheses. Because both dependent and independent variables were included in some of the experiments, they were suitable for hypothesising (unit 3: Let us observe the changes in car tyre, Let us measure force with dynamometer, is friction the same on all surfaces?, Pages one inside another, frictional force in the air, let us feel the resistance of water; Unit 4: Let us discover melting point and freezing point, melting point and melting time, which one melts more quickly?, what happened to money?, Unit 5: oscillating images, Did we see the flower?, let us observe the length of shadow, Unit 6: let us discover nature, how is the weather there?, is the world climate changing?, How?). But hypothesizing was available only in activities in unit 7 (let us make a simple electrical circuit, how can we change the brightness of a lamp in an electrical circuit?, how does the number of batteries influence the brightness of the lamp?). The questions about the variables can appear in centrally held examinations for scholarship and boarding schools for 5th graders. Therefore, teaching the activities suitable for hypothesizing and determining the variables in this context will develop students' scientific process skills and will also help them to prepare for such exams.

Designing experiments was in the course book. The book in which close ended experiments were designed was given to students. The close ended experiments prevent waste of time but limit students' creative thinking (Martin-Hansen, 2002). On the other hand, unavailability of the stages of EDP in other activities can be said to be the restrictions of the book.

Scientific inquiry, which instils in students a great amount of knowledge and skills related to daily life, is an important part of science education. Therefore, teachers, who are the implementers of the book, can apply the activities in the book in a manner so as to understand the nature of scientific research. The activities can also be analyzed in terms of scientific process skills. 